EXPERIMENTAL ACTIVITIES IN GEOGRAPHY EDUCATION

\title{
Students' motivation during experimental activities: An empirical study with GeoBoxes in Germany
}

Nick Naujoks*a , Dietmar Gölitz ${ }^{\mathrm{a}}$, Christiane Tellesch-Bülow ${ }^{\mathrm{a}}$, Marion Händel ${ }^{\mathrm{b}}$, and Jan Christoph Schubert ${ }^{\mathrm{a}}$

${ }^{a}$ Chair for Geography Education, Friedrich-Alexander-University Erlangen-Nuremberg, Germany; ${ }^{b}$ Chair of Educational Psychology and Research on Excellence, FriedrichAlexander-University Erlangen-Nuremberg, Germany

Correspondence concerning this article should be addressed to Nick Naujoks, FriedrichAlexander-University Erlangen-Nuremberg, Regensburger Straße 160, 90478 Nuremberg, Germany, Email: nick.naujoks@,fau.de

All authors are affiliated with the University of Erlangen-Nuremberg, Germany. 


\section{Students' motivation during experimental activities: An empirical study with GeoBoxes in Germany}

This study investigates students' motivation during experimentation in geography lessons by implementing a newly developed experimental kit on soils (GeoBox) in Germany. The study focuses on a first evaluation by means of a one-group pretest/posttest design. Fifth-grade students $(N=166)$ answered a questionnaire pertaining to regular geography lessons (pretest) and took part in eight lessons with GeoBox, followed by a questionnaire regarding the experimental learning phase (posttest). Upon comparison of pretest and posttest scores, the results showed significant intra-individual differences regarding activation and students' motivation. Students valued GeoBox and expected to be successful at tasks that entailed use of the kit.

Keywords: inquiry, motivation, geoscience, experimental kit, multivariate analysis of variance

Word count 7000

\section{Introduction}

Inquiry-based learning is an important approach in science education (L. R. Jones et al., 2013), and especially in geography (Heffron \& Downs, 2012; Lane \& Bourke, 2017b).

According to the National research Council's (2012) framework for K-12 science education, planning and conducting experiments or investigations is a central scientific practice that students should acquire to have access to inquiry processes. Likewise, Heffron and Downs (2012) commented that the study of geography constitutes "an active inquiry process" (p. 13) that comprises scientific methods such as student-driven experiments on geoscience topics. However, according to the results of the Trends in International Mathematics and Science Study (TIMSS), only 10 percent of the students in 27 out of 39 countries reached an international benchmark that considers experimental skills such as planning and interpreting results (Martin et al., 2016). In addition, German students have shown inadequate competencies when conducting experiments on geographical topics (Peter \& Sprenger, 2014), and German as well as international students' interest in curricular geoscience topics such as 


\section{EXPERIMENTAL ACTIVITIES IN GEOGRAPHY EDUCATION}

soils is rather low (Hemmer \& Hemmer, 2010; Trend, 2005). Geoscience topics, however, are particularly conducive to the implementation of experiments in the classroom due to their scientific nature.

To overcome these challenges, this study investigated an experimental kit on soils (GeoBox), with a focus on an evaluation of this kit regarding students' motivation and achievement. The article begins with a classification of experiments within geographical contexts, outlining a model for classroom experimentation and differentiating between experiments in geography and science education. Subsequently, the article discusses the challenges and benefits when incorporating experiments into geography education. The following sections describe the development of GeoBox and explains the kit's formal and pedagogical structure. A literature review summarizes empirical evidence regarding the effects of experiments on performance and motivation. The method section focuses on the design of the study and names the instruments and analyses used to assess students' motivation and performance, and the third section presents the results, with a focus on pretest/posttest comparisons. The article ends with a discussion on the evaluation of the kit and on the consequences deriving from the study's results.

\section{Experiments in geography education}

By allowing for interdisciplinary connections, inquiry-based processes in geography education promote scientific skills such as gathering and visualizing data (Oberle, 2020). The current study, by connecting scientific and geographic inquiry, concentrates on experiments that students conducted on a geoscience topic within a geography class, this approach is in line with the German Geographic Society's (DGfG, 2014) national standards that outline geography as the subject in which educators teach geoscience. 


\section{EXPERIMENTAL ACTIVITIES IN GEOGRAPHY EDUCATION}

Klahr and Dunbar (1988) established the Scientific Discovery as Dual Search (SDDS) model, which applies to experiments across all scientific subjects in school and describes the scientific method. In a "hypothesis space," students familiarize themselves with a problem, generate hypotheses, and plan an experiment to test their ideas. In an "experiment space," students conduct the experiment and determine whether their results prove or disprove their hypotheses. Meinhard (1992) noted that such classroom experimentation involves hands-on activities, the focus of which was the manipulation of physical objects and students' physical activation. Klahr and Dunbar's model of experiments transfers to the frameworks and curricula of geography education (DGfG, 2014; Roberts, 2013a, 2013b). According to German national standards concerning the acquisition of knowledge and methodology, students should conduct simple experiments and be able to "independently pose simple geographical questions and formulate hypotheses to answer these questions, [...] describe and apply simple ways of testing hypotheses, [and] describe in a simple manner to acquire information" (DGfG 2014, 20).

However, while experiments in geography education bear similarities to experiments in physics, chemistry, and biology in these subjects' application of the scientific method, these experiments differ in context. Physical, chemical, and biological experiments have the primary goal of explaining cause-and-effect relationships in natural phenomena, while experiments in geography education always additionally consider "interrelations between the system Earth or its physical geographical subsystems, and humankind or the human geographical subsystems" (DGfG, 2014; Otto et al., 2010; Roberts, 2013a, 2013b). Specifically, the research questions or hypotheses arise from existing social problems to which students refer again when reflecting on results. In consideration of the underlying interrelations, the current study focuses on experiments that are concurrent with the SDDS model and deal with the topic of soils properties (physical geographical subsystems) as a 


\section{EXPERIMENTAL ACTIVITIES IN GEOGRAPHY EDUCATION}

factor for agricultural economy (human geographical subsystems). These experiments present both challenges and benefits that are crucial during implementation in geography classrooms.

\section{Challenges and benefits of experiments}

While empirical studies suggest that students exhibit increased interest in practical, active teaching strategies such as experiments (Bent et al., 2013; Hemmer et al., 2007; Kidman, 2018), teachers perceive the use of these strategies as challenging (Akuma \& Callaghan, 2019; Fögele et al., 2020). International (Maddox et al., 2018; Xuan et al., 2019) and German empirical studies (Hemmer \& Hemmer, 2010; Hof \& Hennemann, 2013) show a lack of implementation and relevance of inquiry-based teaching in geography and identify the challenges and opportunities inherent in promoting experiments as an aspect of inquiry-based teaching in the geography classroom.

Challenges for teachers are either extrinsic and reflect organizational aspects (e.g., lack of time/material; Akuma \& Callaghan, 2019) or they are intrinsic and relate to the teachers' characteristics (e.g., self-efficacy regarding teaching experiments; Miener \& Köhler, 2013). Experimental kits are tools designed to overcome these challenges and promote the adaptation of inquiry-based teaching (Fögele et al., 2020). Most of the existing kits focus on hands-on activities (G. Jones et al., 2012) by providing students with highly guided experiments (National Research Council, 2012). Thereby, these kits address students' interest in practical activity and provide teachers with material that is easy to access. In addition to activating students physically, classroom science experiments should consider research and theories on the effectiveness of teaching and learning (cf. Lunetta et al., 2007), such as cognitive activation as a critical factor for effective teaching of science content (Seidel \& Shavelson, 2016) and for the design of curricular-based instructional materials in geography (Schell \& Mohan, 2013). Activities that promote students' cognitive activation are minds-on 


\section{EXPERIMENTAL ACTIVITIES IN GEOGRAPHY EDUCATION}

activities such as self-generating hypotheses or reflecting on the limitations of experiments can foster students' cognitive activation. According to teaching efficiency literature, experimental kits should not only provide instructions but also encourage students to reflect on their process and generate hypotheses or experiments (Tesch \& Duit, 2004). These demands outlined above influenced the design of a new experimental kit for the geography classroom.

\section{Designing GeoBox}

To summarize, experiments that follow the SDDS model form a key part of the German and international geography curricula and are of interest to students. Nevertheless, implementation of experiments in the geography classroom is challenging for teachers. To resolve this discrepancy, we developed an experimental kit (GeoBox) that fosters experiments in geography education. In combining the rather uninteresting topic with a high-interest teaching strategy, we chose the curricular topic of soils as a factor for agricultural economy (DGfG, 2014), and we developed a learning phase with student-driven experiments. By choosing a curricular topic, we ensured ecological validity regarding the use of GeoBox. For a thorough introduction to all aspects of GeoBox, please refer to the article by [author], which contains lesson examples and preliminary results of a pilot study to this evaluation. 

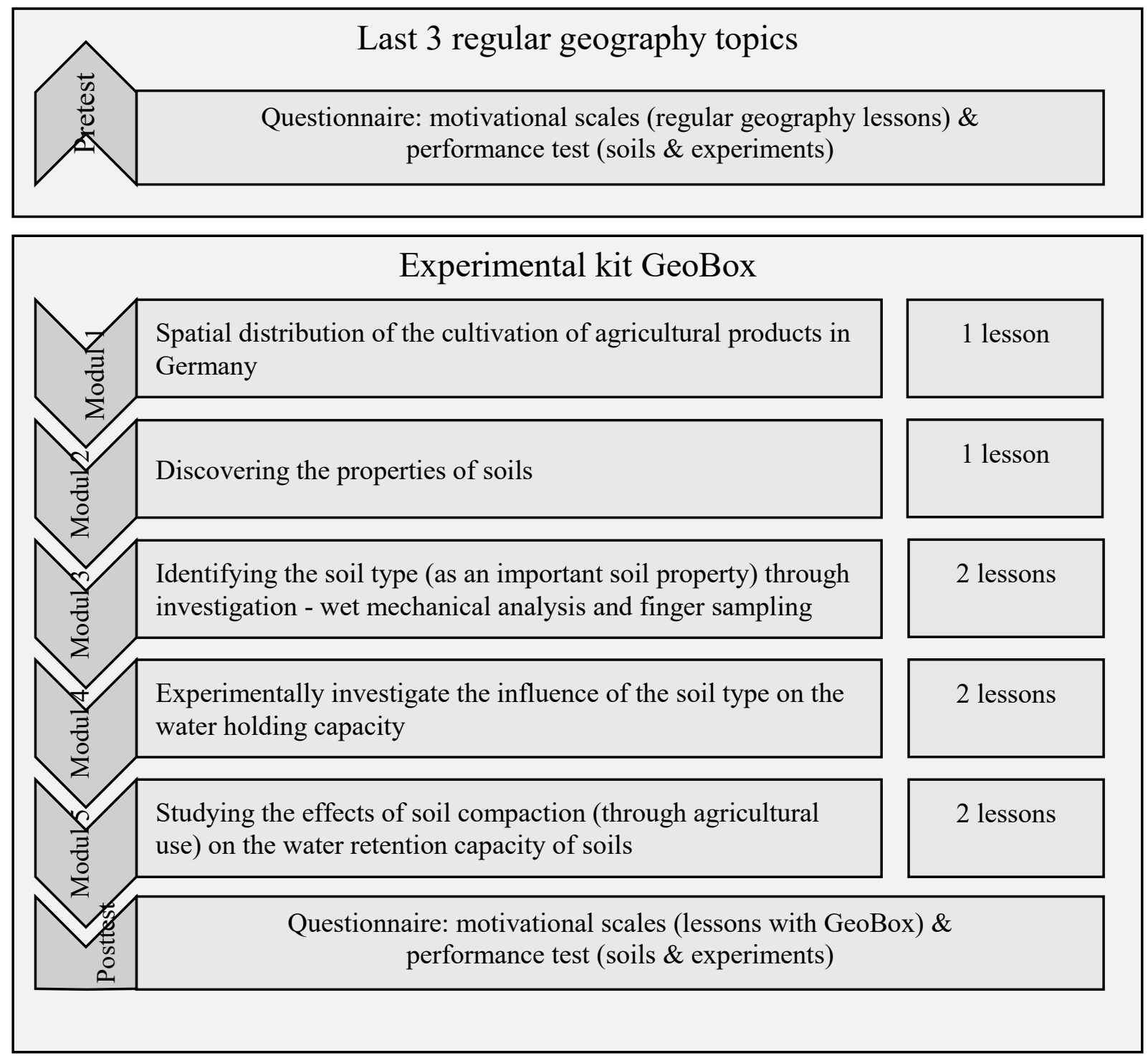

Figure 1. Modules of GeoBox, main content, and duration

The kit consists of five modules, as seen in Figure 1. In consideration of the research on efficient teaching of science, the lessons' instructional strategy combines elements of direct instruction and (guided) scientific learning, thereby providing students with hands-on and minds-on activities. As the students worked in groups of four, teachers provided feedback (e.g., on experimental set-up before performing) and scaffolding (e.g., by suggesting the use of different material) on demand. In line with recommendations by Schell and Mohan (2013), GeoBox focuses on the big idea of sustainable agricultural economies, challenges students' 


\section{EXPERIMENTAL ACTIVITIES IN GEOGRAPHY EDUCATION}

thinking by employing minds-on activities, and offers teachers opportunities for professional development overcoming their perceived challenges.

We developed GeoBox via a multiple-step approach that combined theoretical considerations as well as integrated teachers' and students' needs. Following Edelson's (2002) design-based research approach, GeoBox went through multiple cycles of design and re-design. After designing and implementing a GeoBox version for geography classrooms, we further improved the kit based on partnerships with teachers as experts of practical implementation and educational realization. These partnerships confirmed the needs detected beforehand and added practical needs such as simplification of teacher instructions.

Discussions on equal terms yielded important information, such as the goodness of fit concerning the level of difficulty and elicted to changes such as a clearer introduction of new terms by adding definitions to the worksheets. After multiple cycles of construction and evaluation with students and teachers, we created a final version of GeoBox. To evaluate the kit, existing empirical research concerning effects of experiments on students' performance and motivation was of special interest.

\section{Literature review: Effects on performance}

In our review of prior experiments in school settings, two measures of performance are distinguishable. First, empirical studies investigated knowledge gains in terms of content; several meta-analyses of classroom experimentation showed higher knowledge gains for treatment groups than as a result of traditional teaching strategies such as direct instruction (e.g., Schroeder et al., 2007; Shymansky et al., 1990). Hattie's (2009) Visible Learning Meta ${ }^{\mathrm{x}}$ project summarized an effect size of $d=0.46$ for inquiry-based teaching on students' 


\section{EXPERIMENTAL ACTIVITIES IN GEOGRAPHY EDUCATION}

achievement. $^{1}$

Experimental competencies represent the second measure of performance that is operationalized as knowledge about the scientific method and how to conduct experiments. These competencies are a subset of the competencies that adapt to the National Research Council's scientific competencies and Klahr and Dunbar's (1988) SDDS model. In a first descriptive study, Peter and Sprenger (2014) assessed German secondary school students' experimental competencies in geographic contexts and revealed problems that pertained to all aspects of the SDDS model. Implemention of experimental kits such as GeoBox should improve this specific knowledge.

\section{Literature review: Effects on motivation}

In contrast to cognitive variables, research on classroom experimentation rarely focused on motivational aspects (Riffert et al., 2020). Nevertheless, motivation remains a significant component of successful learning (e.g., Pintrich, 1999).

According to the expectancy-value theory of achievement motivation, students' perceptions of a task's value and their expectancy of successfully completing the task influence their motivation to engage in the learning process (Wigfield \& Eccles, 2000). Expectancy entails learners' beliefs about themselves regarding topic-specific self-efficacy or self-concept. When referring to experiments, topic-specific self-efficacy measures learners' beliefs about their ability to manage similar prospective situations, such as the design of further experiments. Value denotes intrinsic motives such as the situational interest of learners, which is spontaneous and which lessons environmentally activate (Wigfield et al., 2017). Lessons that students perceive as useful and novel should lead to an increased

\footnotetext{
${ }^{1}$ For recent results of the project see http://www.visiblelearningmetax.com/influences/view/inquirybased_teaching
} 


\section{EXPERIMENTAL ACTIVITIES IN GEOGRAPHY EDUCATION}

situational interest in these particular lessons (Kauertz et al., 2010). Kauertz et al. (2011) constructed reliable scales for the aforementioned aspects of motivation (Cronbach's alpha ranged from $\alpha=.67$ to $\alpha=.86$ ) and measured these variables before and after a series of six physics lessons (pretest/posttest design). Therefore, Kauertz et al.'s questionnaire is an appropriate tool to investigate the effects of an experimental kit on students' motivation. In the aforementioned preliminary study, [author] successfully used these scales in a sample that was comparable to the sample of the current evaluation (Cronbach's alpha ranged from $\alpha=$ .73 to $\alpha=.97)$.

Hemmer and Hemmer (2010), whose study focused on the value aspect of motivation, suggested an increase of interest when implementing practical activities such as experiments in geography lessons. Experimental studies in physics (Tröbst et al., 2016) and chemistry (Lunetta et al., 2007; Thompson \& Soyibo, 2002) demonstrated that instructional practices substantially contribute to students' situational interest in lessons that contain experiments. Therefore, students' interest is likely to increase if they can conduct experiments actively. Randler and Hulde (2007) compared biology students' interest across hands-on and teachercentered experiments on soil ecology; as a result, fifth and sixth graders benefited from actively conducted hands-on experiments concerning interest, yielding a small significant effect size $\left(d_{\text {interest }}=0.40\right)$. Generally, students perceived the experimental learning phase as interesting and scored high in well-being regardless of their assigned experimental condition. Whether these differences occur upon comparison of experimental learning activities to regular lessons warrants further investigation.

To assess increases in students' expectancy, Riffert et al. (2020) implemented an inquiry-based learning cycle into sixth-to-eigth grade science classes, which lead to higher academic self-concepts among students. The effect size for the increase was moderate $\left(\eta_{\mathrm{p}}{ }^{2}=\right.$ .06). To examine the effects of self-efficacy on students' science learning, Wan (2019) argued 


\section{EXPERIMENTAL ACTIVITIES IN GEOGRAPHY EDUCATION}

that among other required measures students with hands-on activities, such as experiments, are likely to show higher intrinsic value and expectancy.

Summarizing the literature review, implementing experiments into the classroom seems to foster value as well as expectancy. While most studies in the review focused on one aspect of the expectancy-value theory, the current study investigates both aspects following the procedure by Kauertz et al. (2014).

\section{Research question and hypotheses}

The aim of this study was to investigate differences in students' perceptions between regular geography lessons and geography lessons that featured an experimental kit. The kit combined hands-on activities with cognitive challenges and used curriculum-based materials to overcome potential challenges for teachers. This evaluation of the developed learning materials features two parts: the first part comprises the validation of the experimental kit's effects on gains in knowledge and practical activity, and the second part investigates differences in students' motivation. Accordingly, we posed two research questions.

Q1 (Validity aspects): Does learning with the experimental kit for geography (GeoBox), in comparison to regular non-experimental classroom learning, foster students' practical activity and achievement?

We hypothesized a higher level of practical activity (H1) and higher cognitive activation (H2) for the experimental learning. Furthermore, we expected students' topic-specific knowledge and knowledge of experiments to increase after the experimental learning phase (H3).

Q2 (Motivational effects): How do students' expectancy and value differ between geography lessons that feature an experimental kit in and those that do not?

By contrasting these two types of geography lessons, we expected students to perceive greater 


\section{EXPERIMENTAL ACTIVITIES IN GEOGRAPHY EDUCATION}

expectancy to succeed at tasks that pertained to geography (H4) and to show a higher interest in the lessons that featured GeoBox (H5).

\section{Method}

\section{Design}

We conducted a field study to evaluate the experimental kit GeoBox on the topic of soils as factor for agricultural economy. By using a one-group, pretest/posttest design, the current study tested for differences in students' perceived motivation between regular, nonexperimental geography lessons and lessons that featured GeoBox. Figure 1 and the Designing GeoBox section described the kit's structure and content. We performed an a priori statistical power analysis with $G^{*}$ Power 3.1.9.2 for sample size estimation (Faul et al., 2007) to detect moderate effects via Cohen's (1988) criteria. We calculated requirements for a repeated-measures, multivariate analysis of variance (MANOVA) within factors, and we incorporated eight distinct variables and two measurement occasions in our calculations. With a Type I error of $\alpha=.05$, a power of $1-\beta=.95$, and an assumed correlation among repeated measures of $p=.40$, the projected sample size for one MANOVA is approximately $N_{\mathrm{est}}=72$. This result indicates that we will consider a medium effect $\eta_{\mathrm{p}}^{2}=.06$ as the critical effect size for a single indicator.

To ensure high ecological validity, the classes' regular geography teachers implemented the experimental kit themselves in geography lessons. All participating teachers received training on the kit's material and methodology so that teachers were well prepared to use GeoBox.

Prior to participation in the learning phase with the experimental kit, students completed a questionnaire that assessed subjective, perceived expectancy and value for regular geography lessons (see Figure 1). The questionnaire's items referred to geography 


\section{EXPERIMENTAL ACTIVITIES IN GEOGRAPHY EDUCATION}

lessons of the previous 3 weeks. We refer to this questionnaire as a pretest. After the learning phase encompassing the five learning kit modules, students answered the same questionnaire scales. However, this time, items specifically referred to the five modules of GeoBox, which we refer to as a posttest. Trained assistants and teachers guided students through the questionnaires and read aloud all instructions.

\section{Participants}

Six fifth-grade classes from three different schools participated in the investigation. All schools were non-elite secondary schools located in cities or in rural areas. The socioeconomic status of students across all three schools was comparable. The sample size was $N=166$ students ( $56 \%$ female) and appeared sufficient in size for the detection of the expected effects of our design. A subsample of students $(n=99)$ participated in an additional performance test. The median students' age was 11 years, with a minimum of 10 years and a maximum of 13 years. Each class participated in lessons that their usual respective geography teachers taught. All teachers had at least 10 years of teaching experience and had obtained gradudate degrees in geography education, and none had previously conducted a number amount of student-driven experiments during their classes. They agreed to implement the experimental kit in their regular lessons, and we informed students about the voluntary nature of participation in the pretest and posttest.

\section{Instruments}

To address the validation of GeoBox as a first part of the study, we measured students' cognitive and practical activation via the scales cognitive activating students' experiments and practical activity from the questionnaire on students' perception of teaching for understanding from Kauertz et al.'s (2014) study. While the items for practical activity 


\section{EXPERIMENTAL ACTIVITIES IN GEOGRAPHY EDUCATION}

focused on the use of hands-on activities in class, the items for cognitive activating students' experiments concentrated on the students' perceived cognitive activation through the conducted experiments. Cognitive activation is the intended effect of cognitive challenges.

A self-developed performance test geared toward the content of the GeoBox consisted of two parts. First, 28 true/false items assessed knowledge on soils (e.g., soil properties, clay soil, mechanical analysis, granularity, soil fertility, and available water capacity). These items possessed high curricular validity because of their close relation to the lesson's content. Second, 12 true/false items tested experimental competencies (e.g., knowledge about the structure/process, the hypothesis, and measured values).

To address the second research question and assess students' perceived motivation, we adapted six scales from Kauertz et al.'s (2014) questionnaire on motivational and self-related student variables, which distinguished scales based on whether they measured state or trait components of motivation.

We assessed motivational states of value using the scales from situational interest in geography lessons and topic-specific interest (leisure activities). Perceived competence and topic-specific self-efficacy functioned as scales for motivational states of expectancy. The two scales of interest in geography (value) and self-concept in geography (expectancy) represented motivational traits. Students rated each item on a 4-point Likert scale that ranged from $1=$ totally disagree to $4=$ totally agree. Table 1 shows exemplary items and scale reliability by Cronbach's alpha indicating acceptable to very good internal consistency for all scales. 


\section{EXPERIMENTAL ACTIVITIES IN GEOGRAPHY EDUCATION}

Table 1. Number of items, example item, and reliability (Cronbach's $\alpha$ ) of the scales in use

\begin{tabular}{|c|c|c|c|c|}
\hline & Scale & $\begin{array}{l}\text { Number } \\
\text { of items }\end{array}$ & Example & $\begin{array}{c}\alpha \\
\text { pre/post }\end{array}$ \\
\hline \multirow{2}{*}{ 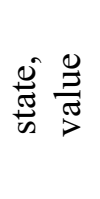 } & $\begin{array}{l}\text { situational interest in } \\
\text { geography lessons }\end{array}$ & 7 & Geography was one of my favorite classes. & $.83 / .87$ \\
\hline & $\begin{array}{l}\text { topic-specific interest } \\
\text { (leisure activities) }\end{array}$ & 6 & $\begin{array}{l}\text { Did you talk to others about the lessons' content } \\
\text { after school? }\end{array}$ & $.80 / .81$ \\
\hline \multirow{2}{*}{ 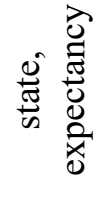 } & perceived competence & 4 & I understood a lot in that class. & $.81 / .84$ \\
\hline & $\begin{array}{l}\text { topic-specific self- } \\
\text { efficacy }\end{array}$ & 5 & I am now able to explain these issues to others. & $.81 / .87$ \\
\hline \multirow{2}{*}{ 苛 } & interest in geography & 5 & I would like to know more about these issues. & $.85 / .87$ \\
\hline & $\begin{array}{l}\text { self-concept in } \\
\text { geography }\end{array}$ & 8 & It is very easy for me to understand such topics. & $.89 / .88$ \\
\hline \multirow{4}{*}{ 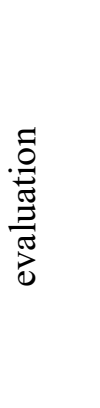 } & $\begin{array}{l}\text { cognitive activating } \\
\text { students' experiments }\end{array}$ & 5 & $\begin{array}{l}\text { The experiments have helped me to find new } \\
\text { explanations. }\end{array}$ & $.81 / .81$ \\
\hline & practical activity & 3 & We were able to do many experiments ourselves. & $.76 / .81$ \\
\hline & content knowledge & 6 & Lighter components cloud the water. & $.43 / .52$ \\
\hline & $\begin{array}{l}\text { experimental } \\
\text { competencies }\end{array}$ & 5 & $\begin{array}{l}\text { Writing down results of an experiment is the last } \\
\text { step in the process. }\end{array}$ & $.54 / .53$ \\
\hline
\end{tabular}

\section{Analysis}

We conducted all analyses in SPSS (IBM, SPSS Statistics, version 25, 2019), and we tested for intra-individual differences of perception between general, non-experimental geography lessons and lessons that featured the experimental kit. Two one-way repeated MANOVAs compared participants' scores to test both sets of hypotheses.

\section{Results}

Confirmation of the validity of the experimental kit, cognitive activation (H1), and practical activity (H2) demonstrated statistically significant differences when comparing means across regular geography lessons and experimental lessons (see Table 2). As expected, students reported higher cognitive and practical activation during the lessons that featured the 


\section{EXPERIMENTAL ACTIVITIES IN GEOGRAPHY EDUCATION}

experimental kit compared to regular, non-experimental lessons. Both scales exhibited significant differences, and in addition, as we tested for differences in content knowledge and experimental competencies (H3), students showed significant improvements in both variables. The effect sizes were substantial for knowledge on soils and knowledge about experiments. Therefore, in response to the first research question, the results of this study affirm all three hypotheses.

Table 2. Results of two one-way repeated measures MANOVAs comparing regular geography lessons to geography lessons with GeoBox

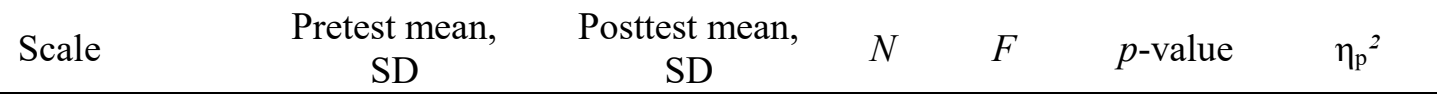

$1^{\text {st }}$ MANOVA: Motivation and activation

\begin{tabular}{|c|c|c|c|c|c|c|}
\hline $\begin{array}{l}\text { situational interest in } \\
\text { geography lessons }\end{array}$ & $2.55,0.69$ & $2.86,0.75$ & 134 & 27.52 & $<.001 * * *$ & .17 \\
\hline $\begin{array}{l}\text { topic-specific interest } \\
\text { (leisure activities) }\end{array}$ & $2.03,0.61$ & $1.91,0.61$ & 134 & 6.14 & $.014^{*}$ & .04 \\
\hline perceived competence & $2.82,0.73$ & $2.93,0.79$ & 134 & 4.06 & $.046^{*}$ & .03 \\
\hline $\begin{array}{l}\text { topic-specific self- } \\
\text { efficacy }\end{array}$ & $2.60,0.72$ & $2.80,0.80$ & 134 & 25.15 & $<.001 * * *$ & .16 \\
\hline interest in geography & $2.30,0.80$ & $2.30,0.84$ & 134 & 0.37 & .545 & .00 \\
\hline $\begin{array}{l}\text { self-concept in } \\
\text { geography }\end{array}$ & $2.76,0.70$ & $2.83,0.73$ & 134 & 5.97 & $.016^{*}$ & .04 \\
\hline $\begin{array}{l}\text { cognitive activating } \\
\text { students' experiments }\end{array}$ & $2.06,0.72$ & $2.94,0.68$ & 134 & 164.69 & $<.001 * * *$ & .55 \\
\hline practical activity & $1.88,0.73$ & $3.23,0.78$ & 134 & 242.87 & $<.001 * * *$ & .65 \\
\hline \multicolumn{7}{|c|}{$2^{\text {nd }}$ MANOVA: Performance test } \\
\hline content knowledge & $0.63,0.10$ & $0.69,0.11$ & 92 & 23.06 & $<.001 * * *$ & .20 \\
\hline exp. competencies & $0.56,0.18$ & $0.65,0.17$ & 92 & 17.50 & $<.001 * * *$ & .16 \\
\hline
\end{tabular}

In our investigation of the second research question, the results showed a significant increase of experiment-related self-efficacy from pretest to posttest measures, yielding a large 


\section{EXPERIMENTAL ACTIVITIES IN GEOGRAPHY EDUCATION}

effect size (see Table 2). The difference between self-concept in geography from pretest to posttest was significant with a small effect size, which suggests a higher self-concept during the learning phase. Additionally, students reported higher perceived competence for the lessons that featured the experimental kit with a small effect size. In our assessment of measures of value, the scales showed differentiating results: no significant difference occurred for students' interest in geography, while topic-specific interest during leisure activities was significantly lower during the experimental geography lessons, thus yielding a small effect size. Situational interest in geography lessons, in contrast, was significantly higher for lessons that featured the experimental kit; this difference showed a large effect size. Because hypothesis $\mathrm{H} 4$ expected significant differences for scales closely related to the actual lessons rather than general constructs, we accepted this hypothesis.

\section{Discussion}

This study is among the first to investigate the motivational variables of experimental kits in geography lessons compared to regular lessons. We used a one-group pretest/posttest design to test for motivational differences between regular geography lessons and lessons that featured an experimental kit on soils as a factor for agricultural economy as a first approach to evaluate the central aspects of the experimental kit GeoBox. While the pretest scales represented students' perceptions of motivation during regular geography lessons, the posttest scales focused on the lessons that featured the experimental kit. Two one-way repeatedmeasures MANOVAs examined differences between pretest and posttest.

\section{Evaluation of the experimental kit}

In accordance with the results of the preliminary study, students reported higher practical activity and greater cognitive activation during the experimental learning activities than in regular geography lessons. Additionally, students scored significantly higher on items that 


\section{EXPERIMENTAL ACTIVITIES IN GEOGRAPHY EDUCATION}

assessed knowledge about content and experiments after the experimental learning activities. These findings indicate three ecologically valid functions of GeoBox: (1) increases in students' activation, (2) gains of knowledge in terms of content, and (3) gains of knowledge about experiments.

First, the experimental kit positively contributed to students' level of activation. Large effect sizes as a result of practical activities and cognitive activating experiments indicate a rare occurrence of these features in regular geography lessons. Encouragement of practical activity is an essential demand of constructivists (Mayer, 2009) and geography education researchers (Battersby \& Hornby, 2006) to stimulate relevant cognitive processes. The experimental kit GeoBox contributes to this demand by providing hands-on experimental activities and tasks that require cognitive activation, such as designing experiments. Furthermore, experiments that incorporated GeoBox appeared to promote cognitive activation, thereby contributing to the demand for cognitive challenges through research on teaching efficiency (Seidel \& Shavelson, 2016). Students' high values on the two activity scales represent the successful practicality of GeoBox in terms of activation. GeoBox seems to overcome the challenges that teachers face when implementing new teaching strategies, such as experiments, by enabling practical and cognitive challenging activities in the classroom that are demanded by geography researchers (Fögele et al, 2020).

Second, significant large effect sizes indicate gains of knowledge through learning with the experimental kit. Future studies should test the differences of knowledge gains in a two-group design with student-driven experiments in comparison to the gains of a control group that attends only regular, non-experimental geography lessons. In the current study, the effect sizes are noticeably higher than the usually reported, small to medium values are (Hattie, 2009; Randler \& Hulde, 2007; Schroeder et al., 2007; Shymansky et al., 1990). 


\section{EXPERIMENTAL ACTIVITIES IN GEOGRAPHY EDUCATION}

Third, students' higher experimental competencies after the experimental learning phase indicate that GeoBox promotes the scientific practices that the National Research Council (2012), the TIMSS science framework (Jones et al., 2013), the German national geography education standards (DGFG, 2014) and international geography education research (e.g. Roberts, 2013 a, 2013 b; Xuan et al, 2019) described. Thereby, GeoBox addresses relevant knowledge gaps of students that Peter and Sprenger (2014) identified. In addition, the quality of the instructional design is in line with research on inquiry-based teaching; according to Matlen and Klahr (2012), settings that teach experiments are the most efficient when direct instruction is considered. The experimental kit GeoBox begins with direct instructional strategies that introduce the topic and continues to less guided hands-on and minds-on activities. Combination of these teaching strategies in this particular sequence from higher to lower guided activities should support cognitive information processing. Additionally, students and teachers reported an adequate level of difficulty and a high level of commitment, which are both likely to support knowledge gains as well as gains in experimental competency. From an evaluative perspective, these results are important because the structure of GeoBox aims more directly at the constructs of cognitive and practical activity as well as achievement. These results are the first hints at the ecological and nomological validity of GeoBox, which appears to produce relevant activation and knowledge directly.

\section{Motivational scales}

Most of the motivational variables showed significantly higher posttest scores, which is in line with the findings by the preliminary study [author]. Students reported higher expectancy values when asked about lessons that featured GeoBox than they did when asked about regular, non-experimental lessons. In our examination of topic-specific self-efficacy and 


\section{EXPERIMENTAL ACTIVITIES IN GEOGRAPHY EDUCATION}

perceived competence as measures of expectancy, we noticed that students felt able to explain their knowledge to others after attending the lessons that featured GeoBox. According to Wan (2019), high topic-specific self-efficacy significantly predicts students' behavioral tendency to learn science in classrooms. Therefore, students' expectancy could explain their commitment to GeoBox and vice versa. While experimenting with GeoBox, each group of students also had the opportunity to self-regulate their learning and decide how they wanted to work on each task. In combination with the aforementioned reports by teachers on students' high level of commitment and appropriate level of difficulty, these aspects of the experimental kit may have positively influenced students' topic-specific self-efficacy and perceived competence.

In addition, general geography self-concept was higher in our assessment of students' perception of the lessons that featured the experimental kit. Because of the short intervention time, a cautious interpretation of differences in a trait aspect of motivation is necessary. Nevertheless, Riffert et al. (2020) could also identify an increase in students' academic selfconcept after implementing inquiry-based teaching strategies in secondary school science classes for one school year.

As we considered the variables pertaining to value aspects of motivation, the results become more differentiating. While students rated their geographical self-concept higher when surveyed about lessons that included GeoBox, there was no difference in their general interest in geography in comparison to the regular, non-experimental geography lessons. In this case, the trait variable of subject interest confirms its stability over time and limits consequences on students' perceptions that result from the use of the experimental kit. Furthermore, the descriptive statistic shows a rather low general interest in geography.

In consideration of research on students' interest in geoscience topics (Hemmer \& Hemmer, 2010; Trend, 2005), students' significant lower interest in the topic of soils as a factor for agricultural economy becomes comprehensible. Following the structures of Kauertz 


\section{EXPERIMENTAL ACTIVITIES IN GEOGRAPHY EDUCATION}

et al.'s (2014) earlier work, the present study asked for topic-specific interest during leisure activities. Results could differ if students were required to judge their topic-specific interest seperately from leisure activities. In contrast, Randler and Hulde (2007) found very high interest and low boredom among students who interacted with a similar topic. These authors suggested that students were interested in either the topic or the experiments. High scores pertaining to situational interest in the specific lessons that featured GeoBox suggest that students valued the hands-on activities and experiments that GeoBox presented as well as the minds-on activities. Because of the low amount of experiments conducted in geography classrooms, literature on motivation suggests that the kit's novelty is a major influence on students' situational interest (Wigfield et al., 2017). In examination of implicit effects, Tröbst et al. (2016) identified a mediation between instructional practice and individual interest by situational interest. Following this finding, and in contribution to situational interest by providing students with experiments, GeoBox may lead students to engage in a specific topic.

\section{Limitations}

The conduction of educational field studies is a challenging endeavor when creating design criteria. On the one hand, scientific guidelines require randomized experiments, which allow for more control throughout the research process and minimize the chances for random effects to occur (Wang \& Morgan, 2010). On the other hand, randomly assigning students to artificial groups instead of keeping them in their daily environment and groupings leads to a violation of ecological validity. Even if classroom settings might constitute difficult confounding variables, researching in pedagogically relevant settings is compulsory to ensure a transfer of empirical findings to school practice (Gläser-Zikuda et al., 2005). Furthermore, because students are aware of their participation in an experiment and may deviate from their natural behavior (Hawthrone effect; Cook, 1962). To minimize this effect, the classes' regular 


\section{EXPERIMENTAL ACTIVITIES IN GEOGRAPHY EDUCATION}

geography teachers introduced students to GeoBox and implemented the learning phase into their geography lessons. In our study, time, place, and setting were exactly as within the regular geography lessons before GeoBox. A different challenge is the availability of reliable and valid assessments in geographical education (Lane \& Bourke, 2017a); the performance test developed for GeoBox is in line with curricular standards and contains items that only assess the content of the learning phase. Therefore, we consider the performance test to be valid in terms of content. Reliability, however, was limited, and further investigations must improve this element.

In summary, we found promising first evidence for a new experimental geography kit with soils experiments that activates students, creates interest, and appears to affect achievement positively. After passing this round of formative evaluation, future research will need to concentrate on stronger experimental designs to evaluate GeoBox in its effects on practical and cognitive activation.

\section{Conclusions and Implications}

GeoBox appears to be a suitable tool for geography education because it grants easy access to hands-on and minds-on activities within experiments. The experimental kit is a tool to link scientific inquiry with geographic inquiry by combining physical geography content with the scientific method and aspects of human geography subsystems (Oberle, 2020; Otto et al., 2010). National problems and challenges were among the reasons for developing and evaluating GeoBox, but we think that the results of our study are relevant to geography educators from all over the world in developing and evaluating curricular learning materials to increase students' knowledge and motivation. In developing experimental kits, researchers and geography educators are encouraged to engage in partnerships on equal terms with teachers to identify and overcome individually perceived challenges. The results from 


\section{EXPERIMENTAL ACTIVITIES IN GEOGRAPHY EDUCATION}

designing GeoBox and its evaluation recommend the pursuit of the following attributes when designing experimental kits: close connection to curricular topics, hands-on and minds-on activities, cost-free availability, and complete material that includes precise instructions and suggestions for teachers. The partnership with the teachers should focus on further improvements such as an appropriate difficulty across classes.

The results of this first evaluation affect further design cycles of and research into the use of GeoBox. The kit promotes students' physical and cognitive activation through the incorporation of hands-on and minds-on tasks. Further development will concentrate on a revision of the material relevant to the potential of activation. There are also variations planned that focus on hands-on or minds-on activities. As discussed in the limitations section, further research will focus on randomized experiments to strengthen our results.

Declaration of interest statement: The authors declare that the research was conducted in the absence of any commercial or financial relationships that could be construed as a potential conflict of interest.

\section{References}

Akuma, V., \& Callaghan, R. (2019). Characterising extrinsic challenges linked to the design and implementation of inquiry-based practical work. Research in Science Education, 49(6), 1677-1706. https://doi.org/10.1007/s11165-017-9671-x

Battersby, J., \& Hornby, N. (2006). Inspiring disaffected students. In D. Balderstone (Ed.), Secondary geography handbook. The Geographical Association.

Bent, G. J., Bakx, A., \& de Brok, P. (2013). Pupils' perceptions of geography in Dutch primary schools: Goals, outcomes, classrooms environment, and teacher knowledge and performance. Journal of Geography, 113, 20-34. https://doi.org/10.1080/00221341.2013.810299

Cohen, J. (1988). Statistical power analysis for the behavioural sciences (2nd ed. ed.). Academic Press.

Cook, D. L. (1962). The Hawthrone effect in educational research. The Phi Kappan Delta, 44(3), 116-122.

Council, N. R. (2012). Framework for K-12 Science Education: Practices, Crosscutting Concepts, and Core Ideas. The National Academies Press.

DGfG, German Geographic Society (Ed.) (2014). Educational standards in geography for the intermediate school certificate with sample assignments (3rd ed. ed.). self-publishing DGfG. 
Edelson, D. C. (2002). Design research: What we learn when we engage in design. Journal of the Learning Sciences, 11(1), 105-121. https://doi.org/10.1207/S15327809JLS1101_4

Faul, F., Erdfelder, E., Lang, A. G., \& Buchner, A. (2007). G*Power 3: A flexible statistical power analysis program for the social, behavioral and biomedical sciences. Behavior Research Methods, 39(2), 175-191. https://doi.org/10.3758/BF03193146

Fögele, J., Luber, L., \& Mehren, R. (2020). Types of student teachers between theory and practice in the subject of geography: Reconstructing orientations using the example of a seminar on experiments. Journal of Geography in Higher Education, 44(2), 310333. https://doi.org/10.1080/03098265.2019.1698524

Gläser-Zikuda, M., Fuß, S., Laukenmann, M., Metz, K., \& Randler, C. (2005). Promoting students' emotions and achievement - Instructional design and evaluation of the ECOLE-approach. Learning and Instruction, 15, 481-495. https://doi.org/10.1016/j.learninstruc.2005.07.013

Hattie, J. (2009). Visible Learning. A synthesis of over 800 meta-analyses relating to achievement. Routledge.

Heffron, S. G., \& Downs, R. M. (Eds.). (2012). Geography for life: National geography standards (2nd ed. ed.). National Council for Geographic Education.

Hemmer, I., Bayhuber, H., Häußler, P., Hemmer, M., Hlawatsch, S., Hoffmann, L., \& Raffelsiefer, M. (2007). Students' interest in geoscience topics, contexts and methods. Journal of Geography Education, 35(4), 184-197.

Hemmer, I., \& Hemmer, M. (Eds.). (2010). Schülerinteresse an Themen, Regionen und Arbeitsweisen des Geographieunterrichts. Ergebnisse der empirischen Forschung und deren Konsequenzen für die Unterrichtspraxis [Students' interest in domains, regions and instructional strategies of geography education. Results of empirical research and consequences for schools]. HGD.

Hof, S., \& Hennemann, S. (2013). Geography teachers in Germany: An empirical study about acquired and required competences. Journal of Geography Education, 41(2), 57-80.

Jones, G., Robertson, L., Gardner, G. E., Dotger, S., \& Blanchard, M. R. (2012). Differential use of elementary science kits. International Journal of Science Education, 34(15), 2371-2391. https://doi.org/10.1080/09500693.2011.602755

Jones, L. R., Wheeler, G., \& Centurino, V. A. S. (2013). TIMSS 2015 science framework. In I. V. S. Mullis \& M. O. Martin (Eds.), TIMSS 2015 Assessment Frameworks (pp. 2960). TIMSS \& PERLS International Study Center, Lynch School of Education, Boston College, and IEA.

Kauertz, A., Kleickmann, T., Ewerhardy, A., Fricke, K., Fischer, H. E., Lange, K., Möller, K., \& Ohle, A. (2010). Different perspectives on science teaching and learning in the transition from primary to secondary level. In M. F. Taşar \& G. Çakmakci (Eds.), Contemporary science education research: Teaching (pp. 419-436). Pegem Akademi.

Kauertz, A., Kleickmann, T., Ewerhardy, A., Fricke, K., Lange, K., Ohle, A., Pollmeier, K., Tröbst, S., Walper, L., Fischer, H. E., \& Möller, K. (2011). Dokumentation der Erhebungsinstrumente im Projekt PLUS [Documentation of instruments in the project PLUS]. Universität Duisburg-Essen. https://duepublico2.unidue.de/receive/duepublico_mods_00035341

Kidman, G. (2018). School geography: What interests students, what interests teacher? International Research in Geographical and Environmental Education, 27(4), 311325. https://doi.org/10.1080/10382046.2017.1349374

Klahr, D., \& Dunbar, K. (1988). Dual space search during scientific reasoning. Cognitive Science, 12(1), 1-48. https://doi.org/10.1207/s15516709cog1201_1 
Lane, R., \& Bourke, T. (2017a). Assessment in geography education: A systematic review. International Research in Geographical and Environmental Education, 28, 22-36. https://doi.org/10.1080/10382046.2017.1385348

Lane, R., \& Bourke, T. (2017b). The inclusion of geography in TIMSS: Can consensus be reached? International Research in Geographical and Environmental Education, 26(2), 166-176. https://doi.org/10.1080/10382046.2016.1178939

Lunetta, V. N., Hofstein, A., \& Clough, M. (2007). Learning and teaching in the school science laboratory: An analysis of research, theory, and practice. In N. G. Lederman \& S. K. Abell (Eds.), Handbook of research on science education (pp. 393-442). Routledge.

Maddox, L. E., Howell, J. B., \& Saye, J. W. (2018). Designing Geographic Inquiry: Preparing secondary students for citizenship. Journal of Geography, 117, 254-268. https://doi.org/10.1080/00221341.2018.1495249

Martin, M. O., Mullis, I. V. S., Foy, P., \& Hooper, M. (Eds.). (2016). TIMSS 2015 international results in science. International Association for the Evaluation of Educational Achievement.

Matlen, B. J., \& Klahr, D. (2012). Sequential effects of high and low instructional guidance on children's acquisition of experimentation skills: Is it all in the timing? Instructional Science, 41(3), 621-634. https://doi.org/10.1007/s11251-012-9248-z

Mayer, R. E. (2009). Constructivism as a theory of learning versus constructivism as a prescription for instruction. In S. Tobias \& T. M. Duffy (Eds.), Constructivist instruction. success or failure (pp. 184-200). Routledge.

Meinhard, R. (1992). Concept process-based science in the elementary school. Oregon Department of Education.

Miener, J.-P., \& Köhler, K. (2013). Experimentelle Arbeitsweisen im Geographieunterricht. Vorstellungen von Geographielehrern zu Chancen und Barrieren [Experimental teaching strategies in geography education. Geography teachers 'beliefs on chances and barriers]. AV Akademikerverlag.

Oberle, A. (2020). Advancing students' abilities through the geo-inquiry process. Journal of Geography, 119(2), 43-54. https://doi.org/10.1080/00221341.2019.1698641

Otto, K.-H., Mönter, L. O., Hof, S., \& Wirth, J. (2010). Das geographische Experiment im Kontext empirischer Lehr-/Lernforschung [Geographic experiments in the context of empirical educational research]. Journal of Geography Education, 38(3), 133-145.

Peter, C., \& Sprenger, S. (2014). Experimenting in geography education - Competencies of secondary school students. Journal of Geography Education, 42(3), 179-191.

Pintrich, P. R. (1999). The role of motivation in promoting and sustaining self-regulated learning. International Journal of Educational Research, 31(6), 459-470. https://doi.org/10.1016/S0883-0355(99)00015-4

Randler, C., \& Hulde, M. (2007). Hands-on versus teacher-centred experiments in soil ecology. Research in Science \& Technological Education, 25(3), 329-338. https://doi.org/10.1080/02635140701535091

Riffert, F., Hagenauer, G., Kriegseisen, J., \& Strahl, A. (2020). On the impact of learning cycle teaching on Austrian high school students' emotions, academic self-concept, engagement, and achievement. Research in Science Education. https://doi.org/10.1007/s11165-020-09918-w

Roberts, M. (2013a). The challenge of enquiry-based learning. Teaching Geography, 38(2), $50-52$.

Roberts, M. (2013b). Geography through enquiry. Geographical Association. 
Schell, E. M., \& Mohan, A. (2013). Road map for 21st century geography education: Instructional materials and professional development. The Geography Teacher, 10(1), 6-14. https://doi.org/doi.org/10.1080/19338341.2012.758597

Schroeder, C. M., Scott, T. P., Tolson, H., Huang, T.-Y., \& Lee, Y.-H. (2007). A metaanalysis of national research: Effects of teaching strategies on student achievement in science in the United States. Journal of Research in Science Teaching, 44(10), 14361460. https://doi.org/10.1002/tea.20212

Seidel, T., \& Shavelson, R. J. (2016). Teaching effectiveness research in the past decade: The role of theory and research design in disentangling meta-analysis results. Review of Educational Research, 77(4), 454-499. https://doi.org/10.3102/0034654307310317

Shymansky, J. A., Hedges, L. V., \& Woodworth, G. (1990). A reassessment of the effects of inquiry-based science curricula of the 60 's on student performance. Journal of Research in Science Teaching, 27(2), 127-144. https://doi.org/10.1002/tea.3660270205

Tesch, M., \& Duit, R. (2004). Experimentieren im Physikunterricht. Ergebnisse einer Videostudie [Experiments in physics lessons. Results of a video study]. Zeitschrift für Didaktik der Naturwissenschaften, 10, 51-69.

Thompson, J., \& Soyibo, K. (2002). Effects of lecture, teacher demonstrations, discussions and practical work on 10th grader's attitude to chemistry and understanding of electrolysis. Research in Science and Technological Education, 20(1), 483-508. https://doi.org/10.1080/02635140220130902

Trend, R. (2005). Individual, situational and topic interest in geoscience among 11- and 12year-old children. Research Papers in Education, 20, 271-302. https://doi.org/10.1080/02671520500193843

Tröbst, S., Kleickmann, T., Lange-Schubert, K., Rothkopf, A., \& Möller, K. (2016). Instruction and students' declining interest in science. American Educational Research Journal, 53(1), 162-193. https://doi.org/10.3102/0002831215618662

Wan, Z. H. (2019). Exploring the effects of intrinsic motive, utilitarian motive, and selfefficacy on students' science learning in the classroom using the expectancy-value theory. Research in Science Education. https://doi.org/10.1007/s11165-019-09891-z

Wang, J., \& Morgan, G. A. (2010). Pre-experimental designs. In N. J. Salkind (Ed.), Encyclopedia of research design (pp. 1081-1086). Sage.

Wigfield, A., \& Eccles, J. S. (2000). Expectancy-value theory of achievement motivation. Contemporary Educational Psychology, 25(1), 68-81. https://doi.org/10.1006/ceps.1999.1015

Wigfield, A., Rosenzweig, E. Q., \& Eccles, J. S. (2017). Achievment values: Interactions, interventions, and future directions. In A. J. Elliot, C. S. Dweck, \& D. S. Yeager (Eds.), Handbook of competence and motivation: Theory and application (2. ed. ed., pp. 116-134). The Guilford Press.

Xuan, X., Jin, Q., Jo, I., Duan, Y., \& Kim, M. (2019). The potential contribution of geography curriculum to scientific literacy. Journal of Geography, 118(5), 185-196.

https://doi.org/10.1080/00221341.2019.1611906 